\title{
PARENTAL CARE IN GUAYAQUILA COMPRESSA WALKER (HOMOPTERA: MEMBRACIDAE)*
}

\author{
BY T. K. WoOD
}

Box 1224, Wilmington College, Wilmington, Ohio 45177

\section{INTRODUCTION}

Egg guarding or parental care is common in the Heteroptera. In the Hemipteran families studied (Bequaert 1925, Eberhard 1975, Melber and Schmidt 1975, 1977), most females desert their offspring before they reach maturity. Typically, parental investment in offspring is provided by females, but in the families Reduviidae (Ralston 1977) and Belostomatidae (Smith 1976), they are replaced by males. In the Homoptera, only females in the Membracidae (Hinton 1976, Wood 1974, 1976a, b, 1977a) and closely related families (Brown 1975) provide parental care of offspring. My studies (unpublished) and those by Hinton (1977) indicate female parental care is common in this family, particularly in the new world tropics.

My studies of 3 membracid species provide evidence for 2 major types of parental care in the family. In the 1 st type, exemplified by Umbonia crassicornis Amyot and Serville and Platycotis vittata F., females remain on eggs until hatch and make a series of feeding slits for nymphs in the branch of the host plant. First instars move off the egg mass and aggregate along these slits with the female positioned below. Parent females actively maintain aggregated nymphs and defend them from potential predators such as adult coccinelids. Successful maturation in the field depends on both nymphs and the parent female remaining together on the same branch until offspring become adults (Wood 1974, 1976a, b).

Entylia bactriana Germar exemplifies the 2nd type of parental investment where the role of the parent female is reduced to the protection of eggs and the 1st two instars. Presumably, reduction of female investment is brought by mutualistic ant associations in this species. Although females are capable of protecting eggs and 1st to 2nd instar offspring, protection is enhanced if ants are in attendance. When females desert 1 st to 2 nd instars, nymphal maturbation in the field depends on protection provided by ants (Wood 1977a).

*Manuscript received by the editor July 26, 1978. 
Haviland's (1925) observations suggested females of Guayaquila compressa Walker may protect eggs. Although detailed observations were not reported, she clearly indicates females relocate offspring and that nymphs readily disperse when disturbed. Such reports require detailed confirmation before attempting a systematic analysis of the types of parental investment within Membracoidea.

\section{METHODS}

The study site was a lowland wet forest at Finca, LaSelva, a field station of the Organization for Tropical Studies in the province of Heredia in Costa Rica. G. compressa was always found in successional or edge areas along the forest on the following host plants: Alchornea sp., Pterocarpus officinalis, Theobroma cacao, Euphorbiaceae and an unidentified vine. Branches or leaves with insects were marked and observations were made daily for 2 to 16 days. Observations of 17 different females on eggs or with nymphs were made during 2 separate trips in August 1976 and 1977. Extensive attempts to increase numbers were made, but individuals tended to be on isolated trees some distance from each other.

\section{RESULTS}

Fermales on egg masses - Eggs are deposited by females in masses surrounded or embedded in a sticky, white matrix on top of plant tissue (Figs. 1 and 2). Two egg masses contained 78 and 88 eggs. Ovipositional sites varied; 6 females placed eggs on the underside of mature leaves on top of the main midrib, while 4 others placed egg masses on branches 6 to 12 inches from the apical meristem. Females sat on egg masses and usually faced the leaf petiole or the apex of the branch. In 1 egg mass, eggs hatched 12 days after deposition, while 9 others were observed for 7 to 10 days before eggs hatched. All egg masses which hatched had females present, while 1 egg mass where the female was removed failed to hatch. A portion of this egg mass without a female was damaged (as if eaten by a predator) the following day and developed mold growth during the subsequent 6 days of observation. This egg mass, deposited within 3 days of an egg mass which hatched, was followed long enough that if there were viable eggs, they should have hatched. 


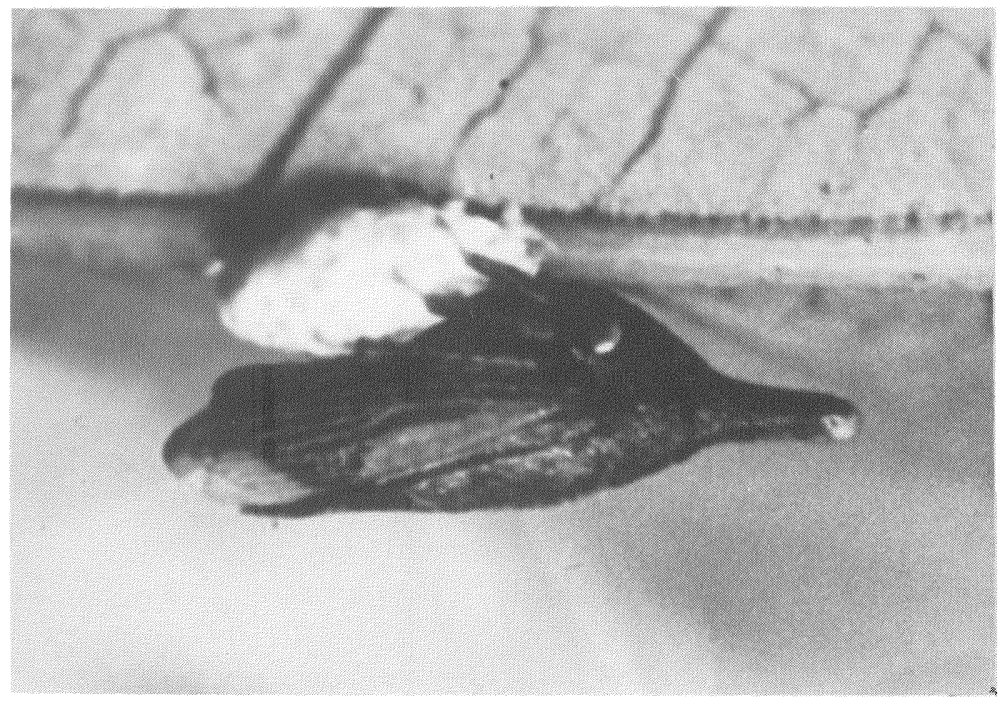

Figure 1. Photograph of female G. compressa on egg mass deposited on plant tissue on the underside of leaf $(\times 7)$.

Females on eggs are sensitive to disturbances and will fly off egg masses. In several cases, touching the branch or leaves caused flight, while other females had to be repeatedly poked with a pencil before taking flight. Six females were disturbed to the point of flight in 12 separate trials. Some of these females simply dropped from the egg mass, but most flew off, landing on plants 5 to 15 feet away or made a circular flight back to the host. In all 12 trials, these 6 females found their way back to egg masses. In 5 trials, females returned within a 24-hour period, while in the remaining 7 trials they returned within 5 to $80 \mathrm{~min}$. Females which could be observed often moved to several plants before locating the tree with the egg mass. Once on the host, they walked up and down branches until finding an egg mass. As they approached egg masses, females appeared to make fewer movements away from the egg mass, suggesting some ability to orient to cues associated with the egg mass (chemical or visual).

Parent female - offspring interaction - First instars associated with 5 parent females averaged 51.8 (range 37 to 60 ) individuals with 
nymphs forming tight clusters occupying 2 to 5 linear $\mathrm{cm}$ of plant surface. Egg hatch observed for 3 egg masses on the underside of the leaf midrib was completed within a 24 -hour period. In 1 egg mass, 15 nymphs after egg hatch lined up along the leaf midrib between egg mass and leaf petiole facing the female next to the egg mass. When the leaf was turned over, all nymphs moved toward the female and clustered together under the egg mass until the leaf was returned to its normal position. During the subsequent $24 \mathrm{hrs}$, the remaining eggs hatched and all 60 nymphs with the parent female had moved 1 foot from the depleted egg mass on the leaf to the main woody branch. The behavior of nymphs and females on 2 other leaves was similar. One group moved 27 inches to another large branch within $24 \mathrm{hrs}$ of egg hatch. Females which deposited eggs on branches moved with their nymphs away from the old egg mass to the apex of the branch, where they became associated with new leaves.

Relocation movements of parent females and nymphs is not only restricted to the $24 \mathrm{hr}$ period after egg hatch. Four aggregations during a 4 to 7-day observation period relocated naturally 1 to 2 times. Relocation is not simply a matter of moving to an adjacent leaf or new shoot, but involves distances up to 3 feet in a 24-hr period. For example, one female and apparently all her offspring were observed to move down a main branch to a fork, then up the 2nd branch to the tip of a lateral twig.

The escape response of parent females and nymphs is different from other treehoppers. Six marked females and their offspring on isolated plants were disturbed by either moving the branch or probing the female with a pencil. Each of 5 females was tested 2 to 5 times and 1 female was tested once for a total of 18 trials. Only 1 trial for a female was done each day, but some females were tested on consecutive days. The amount of "violence" necessary to provoke flight by the female varied from trial to trial. My approaching the branch or touching it was sometimes effective, while in others, females had to be pushed with a pencil 5 to 30 times before taking flight. Distances females flew varied from 1 to 15 feet. Females relocated nymphs in 9 trials within $24 \mathrm{hrs}$; in 2 trials in 1.5 to $4.5 \mathrm{hrs}$, but in 7 trials, they returned within $50 \mathrm{~min}$. (range of 12 to $50 \mathrm{~min}$.). No one female consistently returned faster than others. Females sometimes simply dropped down into the tree, flew off making a 


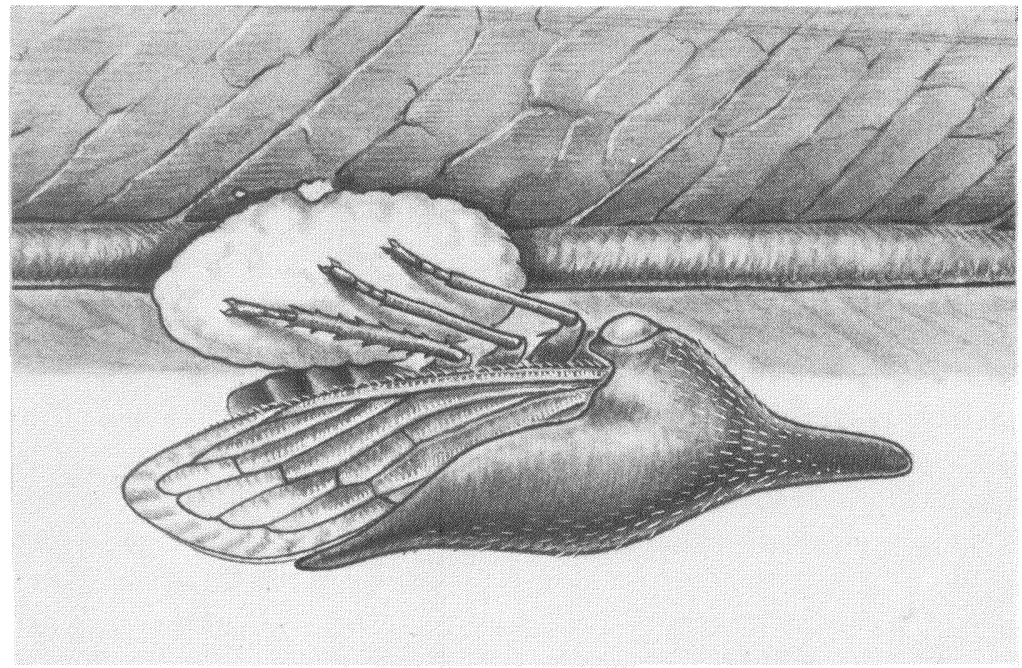

Figure 2. Female of $G$. compressa on egg mass [Original drawing by Sarah Landry].

circular flight back, or flew to adjacent trees with a series of short flights back to the host. One undisturbed female was observed to desert and relocate offspring, but whether this was triggered by a predator could not be determined.

Nymphs dispersed almost immediately in 12 of 18 trials after the female was disturbed. Nymphs moved distances of up to several feet and often reaggregated on new branches. In one trial, when the female was probed once, she fanned her wings which produced an audible clicking while nymphs dispersed up and down the branch. This female did not fly off until all nymphs had dispersed. Careful hand removal of 2 other females triggered immediate nymphal dispersal and reaggregation within a 40 -min period. When the female was removed from 3 aggregations, nymphs remained together for 3 days.

When an injured or crushed nymph was presented, both siblings and female responded. In 1 case, as 7 of 561 st instars moved past the female, she responded by a rapid twisting motion and followed the nymphs for 6 inches. When the female started to move, the 
remaining nymphs dispersed within a minute and walked past her. Lead nymphs stopped at a petiole 12 inches from the original site. After nymphs dispersed from the petiole, the female followed them up the branch, but then returned to the original site where 2 nymphs remained. After a total of 10 minutes, all nymphs were on 9 leaves on 3 different shoots. During the next 8 minutes, the female walked back and forth at the original site before moving to the main branch. Nymphs were still on several leaves but several groups were increasing to the point where 1 leaf had 29 of the 56 nymphs. In the next 70 minutes, the female repeatedly twisted laterally or walked up and down the branch and nymphs continued to consolidate into larger groups. Three groups were formed, one at the tip of shoot, one at its base, and one on the next shoot up the branch. The female after this period positioned herself below the group of nymphs at the base of the shoot. These nymphs then moved to the tip of the shoot, followed by the female. Within 2 min, all but 2 nymphs from the shoot above joined the aggregation. This aggregation then remained in the same place for 24 hours.

Single females on eggs or with offspring were typically the only conspecifics on most host plants. However, 1 host plant about 6 feet high had 2 females with offspring which were observed daily for 9 consecutive days. Initially, the eggs of 1 female had just hatched and nymphs had lined up along the midrib of a mature leaf, while the 2nd female with 501 st instars was located on the same trunk, but 12 inches below the leaf with the $1 \mathrm{st}$ female. During the next $24 \mathrm{hr}$, nymphs with the 2 nd female moved 2 feet up the trunk to new leaves on the apical shoot. The 1 st female and her 60 nymphs moved off the leaf to the trunk while 10 nymphs remained on the leaf petiole. On the 3rd day of observation, both females and their broods had merged together on the terminal growth tip where they remained for the next 5 days. On 2 separate days during this 5-day period, leaves were touched with a pencil, triggering immediate movement of several nymphs down the petiole toward the females. One or both females responded to these nymphs by lateral twisting, back and forth walking, or walking backwards. In both trials, some nymphs went past females, but others which followed were stopped by tapping movements made by a female's prothoracic legs. In neither trial was there massive dispersal and within $5 \mathrm{~min}$., all nymphs had reaggregated at the original site. 
On the 8th day of observation, both females were probed with a pencil until they flew off and nymphs immediately dispersed from the petiole to the main trunk of the plant. Within 23 min., all nymphs had moved down the plant $2 \frac{1}{2}$ feet and reaggregated along the midrib of 3 mature leaves. Consolidation into 1 aggregation took place during the next 17 minutes without the presence of either parent female. Both females made a series of short flights back to the host and at the end of $1 \mathrm{hr}$, one female had located nymphs while the other was rapidly walking up and down branches off the main trunk. This last female, during a 6-min. period, walked to 5 different branches within 12 in. of nymphs. After 24 hrs, both females were with nymphs, but had relocated 18 inches away from the previous observation.

Adult aggregations - One aggregation of 34 teneral adults was observed for 10 days before dispersal. I could not determine if the parent female was present since coloration of teneral adults was similar to that of other parent females. The number of adults decreased during the first 5 days to 28 , then to 15 during the next 4 days, with all individuals gone on the 10th day of observation. In the first 5 days, 2 females deposited eggs, one on the same host, the other on a host 15 feet away. I failed to locate other females on eggs in the surrounding area during a 7-day period after complete dispersal.

This adult aggregation was more sensitive to disturbance than females on eggs or with nymphs. On the first day of observation, all adults were together on the petiole of the leaf. When I accidentally moved the tree trunk, there was an explosive, almost synchronous dispersal with 3 individuals observed 10 feet away. In the following $60 \mathrm{~min}$., individuals moved back to the host and began to form 2 aggregations near the original site. Once on the host, individuals walked up and down branches or flew short distances until coming to the one of the 2 groups where they stopped. At the end of $1 \mathrm{hr}, 30$ insects were in the 2 groups. In the next $48 \mathrm{hrs}, 1$ aggregation attracted all but 5 insects from the other. When this aggregation was disturbed again, dispersal occurred with all 28 adults back together at a new site on the same plant within $24 \mathrm{hrs}$. Without further disruptions, this aggregation remained in the same place for 3 days. 


\section{DISCUSSION}

Female parental investment is well developed in the subfamily Membracinae (classification of Dietz 1975), particularly the tribes Hoplophorionini (U. crassicornis and P. vittata) and Aconophorini (G. compressa). Although the behavior of G. compressa is similar in most respects to species in the Hoplophorionini, certain aspects of nymphal behavior are similar to E. bactriana in the subfamily Smiliinae (tribe: Polyglyptini).

Placement of eggs by female G. compressa on top of plant tissue and held together by an accessory secretion is typical of the Aconophorini (Hinton 1977), while in the Hoplophorionini or Polyglyptini, eggs are inserted into plant tissue. Although all females sit on egg masses, the insertion of eggs into, as opposed to on top of, plant tissue may offer more protection from desiccation, parasites or egg predators due to less exposed egg surface area. Female G. compressa as with some Pentatomids with similar ovipositional habits, may not be able to protect peripheral eggs from parasites (Eberhard 1975).

Female G. compressa on egg masses are extremely sensitive to disturbances while females of $U$. crassicornis and $P$. vittata usually do not desert egg masses, even when given more violent treatment. Physically displaced females of the latter 2 species can relocate egg masses (Wood 1976b, Wood in preparation), but female U. crassicornis do not recognize individual egg masses (Wood in preparation). Whether individual female $P$. vittata or $E$. bactriana recognize their own egg masses has not been tested. Female G. compressa return to egg masses, but this may be an artifact of this species' patchy distribution and low population densities. A dislodged female, which flew 10 or so feet, may encounter an egg mass which has a high probability of being her own through random flights or walking, but whether females recognize their own egg masses must wait until choice tests can be made. Activity which results in egg mass relocation by female $G$. compressa is adaptive since females appear to be necessary in preventing mold growth, protection from egg parasites or predators, and maintaining offspring aggregations.

Protective or defensive adaptations of female $U$. crassicornis on eggs are cryptic coloration and lack of movement, but also involve the shape and hardness of the pronotum (Wood 1975, 1977a). Although mature female $P$. vittata are not physically protected by 
the pronotum, their cryptic coloration and lack of movement make them difficult to find on woody branches of the host plant (Wood 1976b). The pronotum of female G. compressa is similar in shape and hardness to that of mature $P$. vittata, but the black females provide contrast to the green leaf background. Thus, rapid female dispersal producing a startle response in a predator such as an arboreal anole would be a viable alternative for an otherwise unprotected female.

Herding of offspring by parent females within a host plant is unique to G. compressa. Female $U$. crassicornis and $P$. vittata remain with their offspring on the woody branches where eggs were deposited until nymphs reach maturity. Eggs of E. bactriana are deposited in leaves on herbaceous plants but nymphs move from these leaves and reaggregate on new ones after being deserted by females (Wood 1977a). Herding in G. compressa may permit enhanced exploitation of the host plant by reducing localized feeding damage.

Alarm or escape behavior actively involves both female $G$. compressa and offspring, differing significantly from that of $U$. crassicornis or $P$. vittata. Alarm displays by females of the latter species are produced in response to injured nymphs or predators, but nymphs do not disperse from the feeding site, nor are they deserted by parent females (Wood 1976a, b). E. bactriana females place themselves between predator and offspring. Nymphs remain with females initially, but upon prolonged exposure to alarm pheromones or injured females, nymphs disperse from the leaf. Escape behavior of nymphs is also modified by the behavior of various ant species which provide predator protection (Wood 1977a). Thus, the startle response produced by female $G$. compressa provides time to permit nymphal dispersal. Dispersed nymphs reaggregate with or without parent females and maintain an effective nymphal escape response if the parent female is captured or dies from other causes.

Females in a number of membracid species deposit eggs close to each other on a branch even when there appears to be an abundance of oviposition space, suggesting cooperative brood care (Wood, unpublished). G. compressa provides the first evidence to suggest an hypothesis for the adaptive nature of this cooperation. Normal herding behavior on a small host plant means 2 aggregations have a 
high probability of contacting each other. Even if the females were not related, it could be adaptive to merge aggregations to increase the effectiveness of the startle response since 2 females dispersing together or slightly out of phase may provide more time for nymphal dispersal. Even if 1 female is captured, the remaining female can facilitate reaggregation and maintenance of the aggregation. The interaction of 2 or more females may also facilitate normal maintenance of nymphal aggregations, promoting increased feeding efficiency and maturation.

Adult $G$. compressa maintain stable aggregates as do $U$. crassicornis and $P$. vittata. In both of the Hoplophorionini species, aggregations are stable for 15 to 20 or more days. During this period, individuals within the aggregation become progressively more sensitive to disturbances. Individual teneral adult $U$. crassicornis are unpalatable to Anolis lizards, but in addition, employ both an individual and collective cataleptic behavior to reduce predation (Wood 1975, 1977b). Older aggregations disperse explosively about the time of sexual maturity, but do not appear to reaggregate. The explosive dispersal and subsequent reaggregation of adult G. compressa is an extension of nymphal behavior and appears to be an effective response to predators such as anoles which are often seen walking or sunning themselves on branches similar to those where treehoppers are found.

\section{ACKNOWLEDGMENTS}

My thanks to Dr. Glenn Morris and Frank Hale for their help with the field work, and Dr. Gary Hartshorn for the host plant identifications. The faithful and useful criticisms by Dr. David Horn on the manuscript were, as usual, very helpful. Mrs. Carole Kenney typed several manuscript drafts and, as usual, kept her sense of humor. Research funding was provided by NSF grants BNS 74-19764 and BNS 74-19764 A01. I thank Ms Sarah Landry for the excellent drawing in Figure 2.

\section{Literature Cited}

BEquaERT, J.

1935. Presocial behavior among the Hemiptera. Bull. Brooklyn Entomol. Soc. 30: $177-191$. 
Brown, R. L.

1976. Behavioral observations on Aethalion reticulatum (Hem., Aethalionidae) and associated ants. Insect. Soc. 23(2): 99-107.

DeITZ, L. L.

1975. Classification of the higher categories of the New World treehoppers (Homoptera: Membracidae). Tech. Bul. No. 225, N. Carolina Agr. Exp. Station. pp. 1-177.

EBERHARD, W. G.

1975. The ecology and behavior of a subsocial pentatomid bug and two scelionid wasps: Strategy and counterstrategy in a host and its parasites. Smithsonian Contributions to Zoology, No. 205. pp. 1-39.

Haviland, M. D.

1925. The Membracidae of Kartabo. Zoologica. 6: 229-290.

Hinton, H. E.

1977. Subsocial behavior and biology of some Mexican membracid bugs. Ecological Entomology 2: 61-79.

Melber, A., and G. H. Schmidt.

1975. Sozialverhatten zweier Elasmucha-arten (Heteroptera: Insecta). Z. Tierpsychol. 39: 403-14.

1977. Sozialphanomene bei Heteropteren. Sonderdruck aus Zoologica. 127: 19-53.

Nault, L. R., T. K. Wood, And A. M. Goff.

1974. Tree hopper (Membracidae) Alarm Pheromones. Nature (London). 149 (5444): 387-388.

RALSTON, J. S.

1977. Egg guarding by male assassin bugs of the genus Zelus (Hemiptera: Reduviidae). Psyche. 84: 103-107.

SMITH, R. L.

1976. Male brooding behavior of the water bug Abedus herberti (Hemiptera: Belostomatidae). Ann. Entomol. Soc. Amer. 69: 740-747.

Wood, T. K.

1974. Aggregating behavior of Umbonia crassicornis (Homoptera: Membracidae). Can. Ent. 106: 169-173.

1975. Defense in two presocial membracids (Homoptera: Membracidae). Can. Ent. 107: 1227-1231.

1976a. Alarm behavior of brooding female Umbonia crassicornis (Membracidae: Homoptera). Ann. Entomol. Soc. Amer. 69: 340-344.

1976b. Biology and presocial behavior of Platycotis vittata F. (Homoptera: Membracidae). Ann. Entomol. Soc. Amer. 69: 807-811.

1977a. Role of parent females and attendant ants in the maturation of the treehopper, Entylia bactriana (Homoptera: Membracidae). Sociobiology 2 (4): $257-272$.

1977b. Defense in Umbonia crassicornis: The role of the pronotum and adult aggregations (Homoptera: Membracidae) Ann. Entomol. Soc. Amer. 70: $524-528$. 

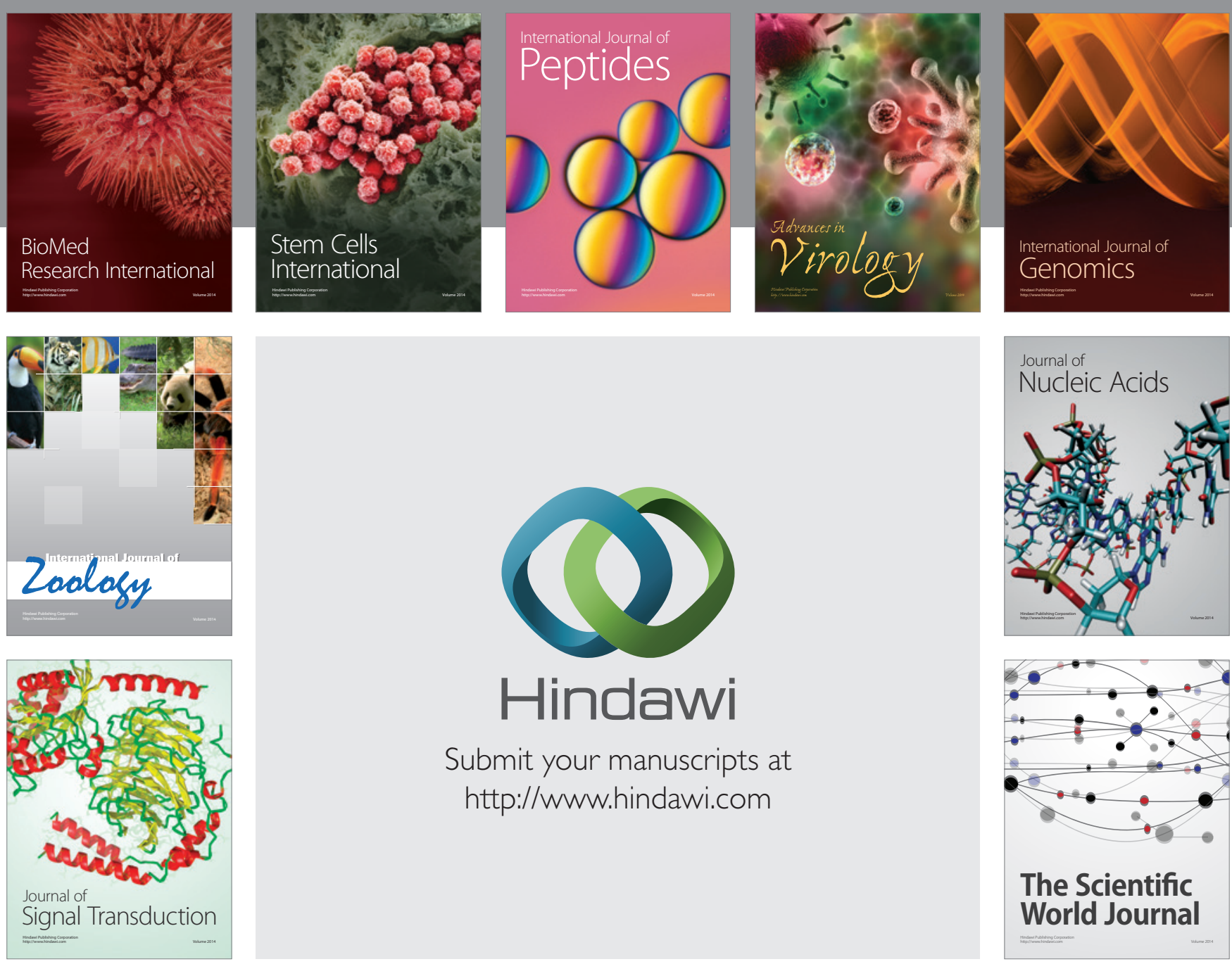

Submit your manuscripts at

http://www.hindawi.com
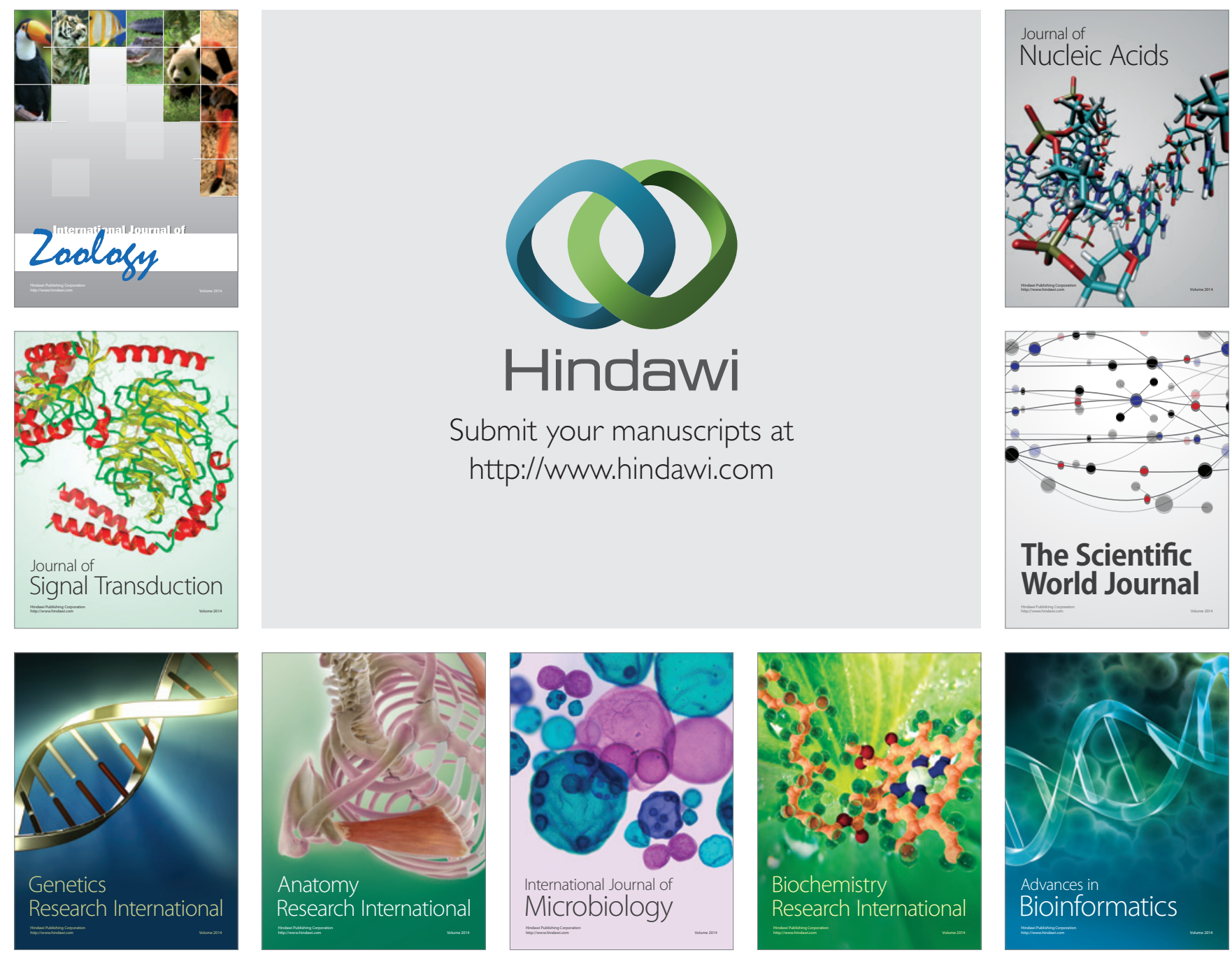

The Scientific World Journal
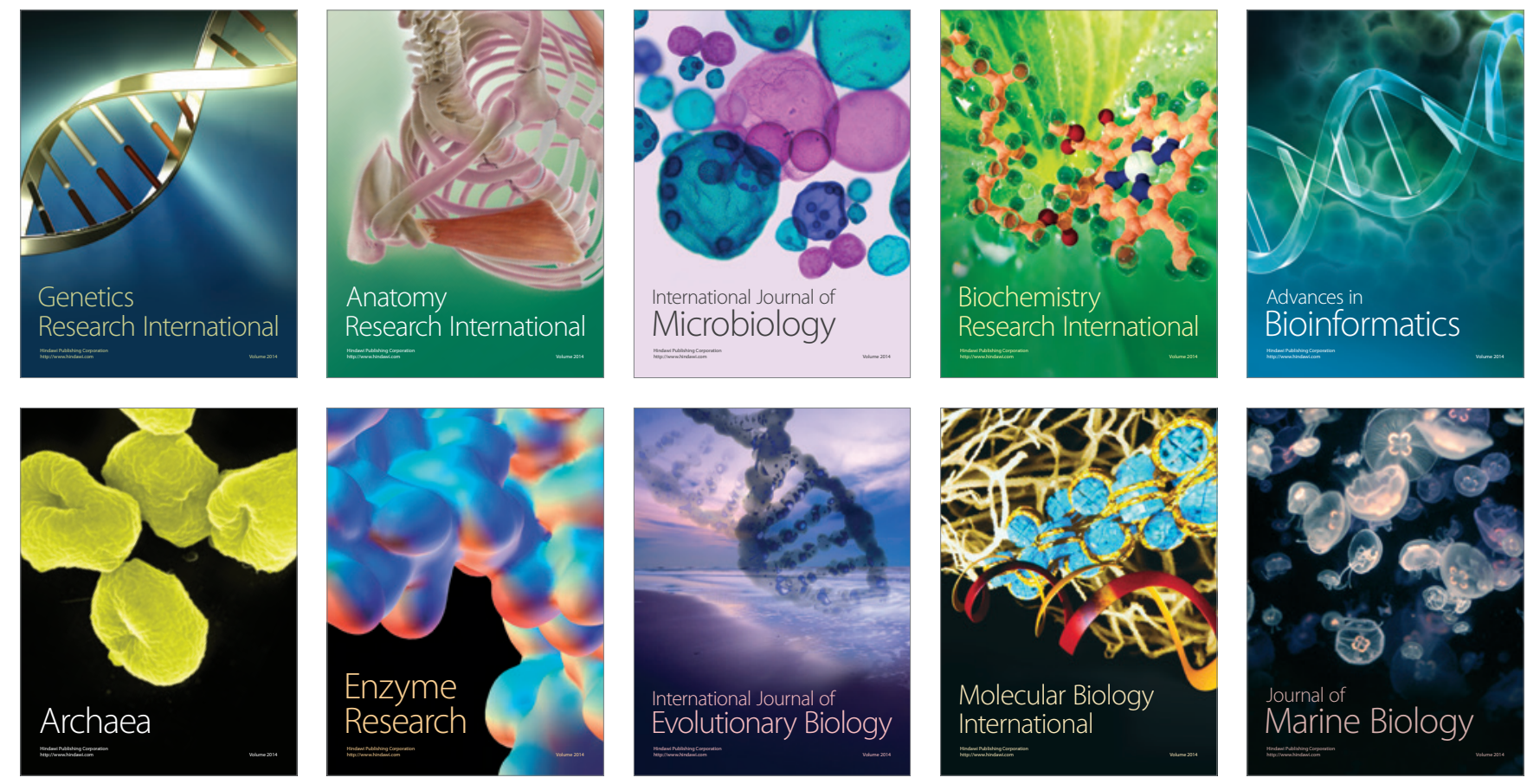